\title{
O PATRIMÔNIO NATURAL COMO SUBSÍDIO AO GEOTURISMO EM UNIDADES DE CONSERVAÇÃO- ILHA GRANDE, ANGRA DOS REIS, RJ
}

\author{
Ana Beatriz Costa Farias ${ }^{(a)}$, Tadeu Tostes de Souza ${ }^{(b)}$ \\ (a) Instituto de Geografia, Universidade do Estado do Rio de Janeiro, anabeatrizcfarias@ gmail.com \\ (b) Instituto de Geografia, Universidade do Estado do Rio de Janeiro, tadeu.tostes@ hotmail.com
}

Eixo: GEODIVERSIDADE, GEOARQUEOLOGIA E PATRIMÔNIO NATURAL

\begin{abstract}
Resumo
Os "Corredores Turísticos" de acordo com o zoneamento turístico do município de Angra dos Reis exploram os atrativos históricos, culturais e naturais. A atividade turística é o uso mais recente do território insular, protegido por diferentes categorias de unidades de conservação e que se enquadra no "Corredor Ilha Grande". O objetivo principal deste trabalho é realizar um levantamento dos potenciais patrimônios naturais presentes nas enseadas de Abraão e Dois Rios visando subsidiar propostas de planejamento na perspectiva do Geoturismo em Unidades de Conservação. O contexto deste estudo é o da fragilidade ambiental frente aos fatores da estruturação turística e o desafio do planejamento territorial na perspectiva de paradigma integrador de acordo com Dèpraz (2008). A metodologia baseia-se nas novas categorias de análise utilizadas para compreender o espaço geográfico segundo Gomes (2013), que aponta as imagens espontaneamente observadas pelo olhar por meio de uma dimensão espacial, cujas categorias são ponto de vista, composição e exposição.
\end{abstract}

Palavras chave: Geoturismo; Planejamento Ambiental; Unidades de Conservação; Percepção da Paisagem.

\section{Ponto de Vista, Composição e Exposição}

O presente trabalho faz parte dos estudos desenvolvidos por alunos de graduação e pós-graduação no Núcleo de Ensino e Pesquisa em Planejamento Territorial (NEPPT) do Instituto de Geografia - UERJ, na linha de pesquisa voltada para as questões do patrimônio em unidades de conservação e a perspectiva do Geoturismo. O recorte espacial é a Ilha Grande, distrito de Angra dos Reis que localiza-se na Baía da Ilha Grande entre as coordenadas $22^{\circ} 50^{\prime}-23^{\circ} 20^{\prime} \mathrm{S}, 44^{\circ} 00^{\prime}-44^{\circ} 45^{\prime} \mathrm{W}$, litoral sul do estado do Rio de Janeiro, região da chamada "Costa Verde", sub-unidade turística de Praias e Escarpas Serranas. Morfologicamente possui praias e planícies estreitas constituídas de sedimentos quaternários que estão localizadas entre a escarpa da serra da Bocaina e o oceano Atlântico. Maior ilha do estado do Rio de Janeiro e a terceira do país, possui área de $187 \mathrm{~km}^{2}$ de acordo com a Prefeitura Municipal de Angra dos Reis, muito embora outros órgãos consideram a área de aproximadamente $193 \mathrm{~km}^{2}$ de extensão. É reconhecida internacionalmente por apresentar paisagem que contrasta relevo dissecado de serra coberto por densa floresta tropical, planície flúvio-marinha com manguezais e restinga, cachoeiras. Ressalta-se que o 


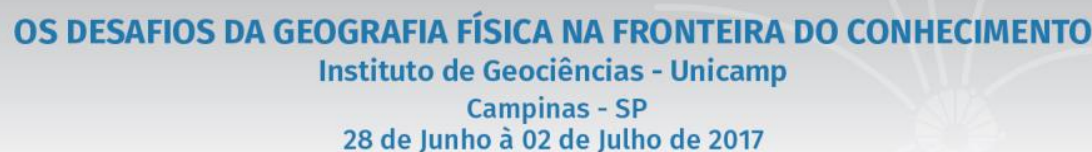

28 de Junho à 02 de Julho de 2017

desconhecimento do meio físico e de sua importância para o planejamento territorial tem levado à ocupação desordenada e à perda de atributos importantes para o turismo.

De acordo com o zoneamento turístico do município de Angra dos Reis ("Corredores Turísticos"), no Corredor Ilha Grande são explorados os atrativos históricos, culturais e naturais. A atividade turística é o uso mais recente deste território insular, protegido por diferentes categorias de unidades de conservação. O objetivo principal é fazer um levantamento dos potenciais patrimônios naturais presentes na Vila do Abraão e no Povoado de Dois Rios visando subsidiar propostas de planejamento na perspectiva do Geoturismo em Unidades de Conservação. O contexto desse estudo é o da fragilidade ambiental frente aos fatores da estruturação turística e o desafio do planejamento territorial na perspectiva de paradigma integrador de acordo com Dèpraz (2008). A metodologia baseia-se nas novas categorias de análise utilizadas para compreender o espaço geográfico segundo Gomes (2013), que aponta as imagens espontaneamente observadas pelo olhar por meio de uma dimensão espacial, cujas categorias são ponto de vista, composição e exposição.

Por se tratar da visibilidade de elementos geoturísticos de uma dada área, torna-se coerente a abordagem de Gomes, na qual, essas categorias, já referidas anteriormente, são constituídas originalmente por meio de uma dimensão espacial. São elas: Ponto de Vista, Composição e Exposição. Ponto de Vista é um dispositivo espacial, na qual no seu sentido concreto é usado para designar lugares que oferecem uma visão panorâmica, de onde se pode observar uma paisagem, por exemplo. Porém, tem o sentido metafórico de opinião, tal qual quando olhamos a paisagem, escolhemos a posição do nosso olhar, como olhar, e a partir dai o físico se adequa, onde serão determinados o ângulo, a direção, a distância, entre outros atributos posicionais. "A expressão estabelece, portanto, uma relação direta entre o observador e aquilo que está sendo observado. Já Composição seria o conjunto estruturado de cores, formas ou coisas, resultado de uma combinação que gera algo novo, formado pela junção de diversos elementos que possui um aspecto essencial, o jogo de posições. Então, é a forma de dispersão desses dados que juntos dá origem ao novo elemento e corresponde a sua espacialidade. Há uma ordem espacial que é a chave da dispersão. De acordo com Gomes (Op.cit, 2013:21), “a paisagem é sempre uma composição. Formas do relevo, diferentes tipos de cobertura vegetal, ocupação das terras, entre outros elementos se associam de modo original e configuram uma paisagem" E pela categoria Exposição, tem-se a questão voltada para a posição de exterioridade. $\mathrm{O}$ autor coloca a importância de se compreender as coisas segundo uma classificação que institui o que deve ser exibido e o que deve ser escondido. De acordo com Gomes (2013): 
"Lugares de exposição são lugares de grande e legitima visibilidade. O que ali se coloca tem um comprometimento fundamental com a ideia de que deve ser visto, olhado, observado, apreciado, julgado. Isso também significa dizer que socialmente estabelecemos lugares onde essa visibilidade deve ser praticada, segundo complexas escalas de valores e significações. [...] Dessa maneira, as dinâmicas que afetam a visibilidade, aquilo que deve ser reunido na compreensão da vida social. Essa constatação já poderia ser uma justificativa suficiente para a afirmação da relevância do olhar geográfico." (Gomes, 2013, p. 23).

O conceito de visibilidade depende da morfologia do sítio, da existência de um público e da produção de uma narrativa dentro da qual aquela coisa, pessoa ou fenômeno encontra sentido, merecendo, assim, destaque. Destaca-se a cartografia do olhar que, de acordo com Gomes (Op.Cit), o tipo de espaço, o lugar ocupado, a rede de relações dessa posição podem atuar como critérios que guiam o olhar e o interesse, conferindo diferentes graus de visibilidade às coisas. Já o conceito de paisagem, seria uma dimensão composicional, ou seja, o de associação de coisas pela posição em que se encontram que é uma das bases do raciocínio geográfico e também definidas pelo ponto de vista, ou melhor, o enquadramento do olhar, seu delimitador. Dependendo da posição em que nos encontramos, do ângulo, da distância, diferentes coisas aparecerão e, podem parecer mais ou menos importantes que outras. Por último, o conceito de espaço que o autor chama a atenção sobre a dificuldade de definição:

"Na geografia passamos, ás vezes, horas argumentando, escrevemos muitas páginas para tentar dizer que o espaço não é um mero reflexo da sociedade, que ele não é determinado por ela, ele é uma condição necessária para que a sociedade se organize e consiga viver sob determinadas formas, ele é um elemento estrutural e estruturante. Tudo isso está contido em uma pequena sequência de alguns poucos minutos, eis o poder da imagem.” (Gomes, 2013, p. 119).

\section{Geoturismo e Geodiversidade}

A preservação do patrimônio geológico e sua divulgação através do turismo são assuntos ainda recentes e encontram-se inseridos em uma nova ramificação das geociências denominada por Geoconservação. $\mathrm{O}$ conjunto do patrimônio geológico de uma região constitui sua Geodiversidade, termo que denomina a variedade de elementos abióticos da natureza. A Geodiversidade cada vez mais aparece como uma das principais bases do Geoturismo, atraíndo visitantes, cujo interesse principal se dá na observação e descoberta dos aspectos geológicos-geomorfológicos que constituem o patrimônio natural existente na Ilha Grande.

De acordo com Guerra e Marçal (2006), a atividade turística pode estar intimamente relacionada com o meio físico, em especial, aquela vinculada à exploração das belezas naturais de uma determinada área, demonstrando o crescente interesse da Ciencia Geográfica em seu estudo. Para Ruchkys (2007, in Instituto Brasileiro de Turismo), o Geoturismo seria:

“[...] um segmento da atividade turística que possui o patrimônio geológico e geomorfológico como atrativo principal e busca sua proteção por meio de conservação de seus recursos da sensibilização 
do turista, utilizando, para isto, a interpretação deste patrimônio, o tornado acessível ao publico leigo, além de promover a sua divulgação e o desenvolvimento das ciências da Terra." (Ruckys, 2007).

Destaca-se que o Geoturismo objetiva preencher uma lacuna do ponto de vista da informação ao possibilitar que o turista não só contemple as paisagens, como também, entenda o embasamento dos processos geológicos e geomorfológicos responsáveis por sua formação. Portanto, o Geoturismo pode ser considerado uma atividade baseada na Geodiversidade, tornando-se um novo segmento no turismo em áreas naturais e realizado por pessoas que possuem o interesse em conhecer mais sobre os aspectos geológicos e geomorfológicos de um determinado local.

De acordo com Farias (2015) a Geodiversidade aparece então como campo preponderante para a análise das categorias propostas por Gomes e que embasam o conceito de Geoturismo adotado. A importância dos aspectos geológicos e geomorfológicos enquanto atrativo se destaca no circuito utilizado como recorte de estudo, é possível destacar alguns pontos onde os conceitos de Ponto de Vista, Composição e Exposição são facilmente identificados na relação de atratividade ao Geoturismo. São sete pontos destacados no circuito Vila do Abraão - Dois Rios. A Praia Preta, cujo nome remete a característica física da paisagem, localizada na foz do Córrego do Abraão, sua areia tem coloração escurecida devido à presença de minerais como a ilmenita, magnetita e biotita, que ali são depositados pelas águas do córrego; o Poção, que constitui um patrimônio natural, onde as características geológicas e geomorfológicas ficam mais evidentes (deslocamento de rochas, movimentos de massa, contato litológico), e assim, nomeia atualmente esse ponto; a Cachoeira da Feiticeira, que possui um destaque natural com uma queda d'água de 15 metros e com exposição de afloramento rochoso que forma um poço cercado por blocos de rocha; a praia de Dois Rios, uma enseada voltada para o oceano e delimitada por dois rios que ali deságuam, além de uma formação de restinga; os rios Barra Grande (ou Andorinhas) e o Barra Pequena, cercada por maciços rochosos; e por ultimo, os registros arqueológicos encontrados em rochas localizadas nos rios, marcas de amoladores utilizados pelos sambaquis em ocupações pretéritas da localidade.

\section{Patrimônio Natural e Unidades de Conservação}

O patrimônio é compreendido como os elementos materiais e imateriais, naturais ou culturais, herdados do passado ou criados no presente, no qual um determinado grupo de indivíduos reconhece sinais de identidade. Os elementos naturais incluem os aspectos físicos, biológicos e geológicos excepcionais, habitats de espécies animais e vegetais ameaçados e zonas que tenham valor científico, de conservação ou estético. O valor científico se encontra em áreas que contenham formações ou fenômenos naturais 
relevantes para o conhecimento da história natural do planeta. A importância ecológica se aplica ao habitat de espécies ameaçadas ou em risco de extinção ou detentoras de processos ecológicos e biológicos importantes. O valor estético é aquele que se expressa nas paisagens notáveis e de extraordinária beleza natural ou em condição de exceção. O patrimônio expressa a solidariedade que une aqueles que compartilham um conjunto de bens e práticas que os identificam. A proteção se efetiva no envolvimento das comunidades que os detém, num processo que inclui a identificação, a conservação, o estudo e a difusão dos bens patrimoniais.

Nesse contexto, a necessidade dos subsídios de patrimônios naturais, Geodiversidade e Geoturismo são fundamentais para o ordenamento de unidades de conservação, como apresentado aqui na Ilha Grande. É um embasamento que não visa apenas à conservação dos patrimônios que apresentam fragilidade ambiental, ou níveis altos de degradação, e sim busca a partir do entendimento da relação comunidade, órgãos públicos e interesses turísticos o melhor método para se traçar um planejamento justo, com menor nível de impactos e com retorno favorável para todos os agentes envolvidos. Além da prática da educação ambiental e da preservação da identidade e memória dos povos locais.

\section{REFERENCIAS}

BRILHA, J. Enquadramento legal de suporte à protecção do património geológico em Portugal. In Cotelo, J.M. Neiva, A. Ribeiro, L. Mendes Victor, F. Noronha, M. Ciências Geológicas: Ensino, Investigação e sua História. Associação Portuguesa de Geólogos, Volume II, pp. 443. Magalhães Ramalho (Edts.) 2010.

DEPRÀZ, S. Géographie des espaces naturels proteges: genèse, principes et enjeux territoriaux, Paris, AC 2008.

FARIAS, A. B. C; NUNES, G. F.; GAMA, S. V. G. da. A Visitação Pública e a Perspectiva do Geoturismo no Circuito Abraão e Saco do Céu- Ilha Grande, Angra dos Reis (RJ/Brasil). In: XV Encuentro de Geógrafos de América Latina, 2015, La Habana - Cuba. Anais eletrônicos, CD-ROM ISBN: 978-959-7167-50-1.

GOMES, P. C. da C. O Lugar do Olhar: elementos para uma geografia da visibilidade. Rio de Janeiro: Bertrand Brasil. 2013.

GUERRA, A. J. T.; MARÇAL, M. S. Geomorfologia aplicada ao turismo. In: GUERRA, A. J. T.; MARÇAL, M. S. Geomorfologia Ambiental. Rio de Janeiro: Bertrand Brasil. 2006.

MOREIRA, J. C. Geoturismo e interpretação ambiental. Ponta Grossa: Editora UEPG. 2011. 


$\begin{aligned} & \text { XVII Simpósio Brasileiro } \\ & \text { de Geografia Fisica Aplicada }\end{aligned}$
$\begin{aligned} & \text { I Congresso Nacional } \\ & \text { de Geografia Física }\end{aligned}$

RUCHKYS, U. A. Patrimônio Geológico e Geoconservação no Quadrilátero Ferrífero, Minas Gerais: Potencial para a Criação de um Geoparque da UNESCO. (Tese- Doutorado) Belo Horizonte: Instituto de Geociências, Universidade Federal de Minas Gerais. 2007 